\title{
Mental Health Support for COVID-19; A Retrospective Report on the Psychosocial Response Strategy in Lagos, Nigeria
}

\section{Yewande Oshodi ( $\nabla$ yewyoshodi@yahoo.co.uk)}

Lagos University Teaching Hospital https://orcid.org/0000-0002-4244-0739

Charles Umeh

University of Lagos, College of Medicine

\section{Modupe Sokunbi}

Lagos State Ministry of Health

\section{Tolu Ajomale}

Lagos State Ministry of Health

\section{Babatunde Fadipe}

Lagos University Teaching Hospital

\section{Omotayo Ajirotutu}

Federal Neuropsychiatry Hospital Yaba

\section{Jaiyeola Kajero}

Federal Neuropsychiatry Hospital, Yaba, Lagos

\section{Chizoba Fashanu}

Clinton Health Access Initiative, Abuja

\section{Oluyemisi Nyamali}

Federal Neuropsychiatry Hospital Yaba, Lagos

\section{Olurotimi Coker}

Lagos State University Teaching Hospital

\section{Mofeyisope Akinyosoye}

Lagos State Ministry of Health

\section{Anne Ejiegbu}

Lagos University Teaching Hospital

\section{Adefemi Adeoye}

Federal Psychiatry Hospital Yaba, Lagos

\section{Gbonjubola Babalola}

Tranquil and Quest Behavioural Health Limited

\section{Adejoke Abiodun}

Lagos State Ministry of Health

\section{Oluwatoyin Olusanya}

Lagos State Health Services Commission

\section{Chris Chiadika}

Lagos State Health Service Commission

Israel Owolabi 
Lagos University Teaching Hospital

\section{Chigozie Ekperechukwu}

Lagos University Teaching Hospital

\section{Aduragbemi Samuel}

Lagos State Ministry of Health

\section{Azizat Lebimoyo}

Lagos State University Teaching Hospital

\section{Bolutife Oyatokun}

Happy Family Hospital Lagos, Nigeria

Hussein Abdur-Razzak

Lagos State Ministry of Health

\section{Moyosore Anibaba}

Lagos State Ministry of Health

\section{Babatunde Saka}

Global Emerging Pathogen Treatment Consortium

\section{Bisola Adebayo}

Lagos State University College of Medicine

\section{Ismael Abdus-Salam}

Lagos State Ministry of Health

\section{Olusegun Ogboye}

Lagos State Ministry of Health

\section{Christopher Bode}

Lagos University Teaching Hospital

\section{Akin Osibogun}

University of Lagos College of Medicine

\section{Akin Abayomi}

Lagos State Ministry of Health

\section{Research}

Keywords: Covid-19, Africa, Mental, Psychosocial, Pandemic, Nigeria

Posted Date: December 1st, 2020

DOI: https://doi.org/10.21203/rs.3.rs-114214/v1

License: (c) (i) This work is licensed under a Creative Commons Attribution 4.0 International License. Read Full License 


\section{Abstract}

Background:The COVID-19 pandemic has been described to have significant effects on the mental health and emotional well-being of people all over the world generally. This study aimed at describing the set up and functions of the psychosocial support service for the COVID-19 response in Lagos South West Nigeria.

Methods: A retrospective and descriptive overview of the psychosocial support for covid-19 patients supported in Lagos, Nigeria over a four-month period. Remote interventions given included Psychological first aid, counselling, psycho pharmacology, and virtual support group sessions.

Results: The Psychosocial care provided was a part of the Covid-19 outbreak response strategy in Lagos State, Nigeria. Over 43,000 support calls were made to Covid-19 positive persons; 1,316 hospitalised patients were supported remotely during isolation and more than half declined admission, opting to self-isolate at home instead. Psychosocial home care support group sessions and discharge support groups held. Liaison with all other thematic pillars of the response was key.

Conclusion: A comprehensive multidisciplinary mental health and psychosocial support service is an integral part of the management strategy during the pandemic response. The Psychosocial support by the Lagos Covid-19 response presents a practical reproducible approach.

\section{Introduction}

The novel Coronavirus, (2019-nCov) also known as SARS-Cov-2 by the international committee on Taxonomy of viruses), often referred to as COVID-19, began as a very contagious local respiratory disease in Wuhan region of China. The spread increased rapidly and globally and the World Health Organization (WHO) later declared this a pandemic on March 11, 2020 as the new coronavirus continued to spread across the world. Nigeria reported its first confirmed case of COVID-19 on the 27th of February. 2020 and this was also the first case in Sub-Saharan Africa.

Lagos was the epicenter of the outbreak in Nigeria with infectivity figures rising from 1 case to 4053 cases in three months. The Lagos State Emergency Response Centre is the organ of the COVID-19 state response system that was set up by the Lagos State Ministry of Health (LSMH). The COVID-19 response plan is implemented by the Emergency Operation Centre (EOC), which is the operational arm of the Incident Command System (ICS). Four weeks to the discovery of its index case, Lagos state set-up, an Incident Command System (ICS). The ICS is the body responsible for defining the strategic direction of the State's response to the COVID-19 pandemic. The ICS is led by the Governor of Lagos State Babajide Sanwo-Olu, who serves as the Incident Commander. The Incident Commander is ably and actively assisted by the Deputy Incident Commander in the person of Prof. Akin Abayomi, the Honourable Commissioner for Health. Within the ICS is the Emergency Operations Centre (EOC). The EOC is led by an Incident Manager, who drives the day-to-day activities involved in the State's response; (Lagos incident response plan). The EOC is made up of 10 thematic areas namely, Laboratory, Case Management, Surveillance and Epidemiology, Psychosocial Support, Port entry, Risk mobilization and Communications, Decontamination, Laboratory, Infection Prevention and Control along with Research thematic areas ${ }^{6}$. The structure adopted by Lagos State provides easy escalation of all activities and requirements up and down the chain. This allows all parts of the State's response to function seamlessly.

The Coronavirus outbreak was observed to have a significant and deleterious emotional impact, further complicating an already serious medical situation. The effects of social isolation during the lockdown, the fear of 
contagion, the loss of loved ones uncertainty of survival if infected along with the felt and imagined stigma following recovery all present the several layers of mental health morbidity experienced by COVID-19 survivors. ${ }^{7}$, Other social and psychological factors as well as mental health issues are associated with the condition.

The provision of psychosocial support is an important part of relieving the suffering that may occur as a result of infection with the virus and in demonstrating the caring aspect of the intervention. Psychosocial care/support can facilitate operations by encouraging openness and a better reception by the community to health messages and to adopting behavioral change.

In the absence of similar studies in sub-Saharan African countries, this study provides an important framework for similar response for out breaks in low-resource settings as it reports on the service description and the three-month period of the COVID-19 psychosocial support strategy in Lagos Nigeria.

It was in this light that this the researchers set out to articulate the setup, functions and scope of the psychosocial support service for the COVID-19 response in Lagos South West Nigeria over a period of the response.

\section{Methodology}

Design and Setting - This study was designed as a retrospective and descriptive overview of the psychosocial support strategy and service delivered during a four-month period (May 7th to September 30th 2020) of the COVID19 pandemic response in Lagos Nigeria.

Team members were in different locations across the Lagos metropolis and worked remotely either from home or their office spaces. All on boarding trainings were done virtually via the zoom platform. Supervision sessions and weekly team peer supervision sessions were also scheduled remotely on the virtual platforms.

Procedure - The multidisciplinary team comprised of volunteers that were recruited based on indication of interest to volunteer in the service response and also as recommended by existing volunteers at different points of team expansion. The Psychosocial support team commenced initially as a 4-man team and dynamically grew with the scope of the response to a psychosocial response team made up of 150 multidisciplinary skilled mental health and allied personnel.

Volunteer psychosocial team members received mandatory training sessions. Training sessions were on basic psychological first aid delivery, skills on breaking of bad news using the SPIKES model, telephone etiquettes skills, update on coping skills and pathways to care in the response system. All interventions utilized for psychosocial support were deployed virtually at all levels to deliver support, counsel, provide appropriate intervention as needed and provide guidance for clients served. Escalation paths were activated as needed to other relevant thematic pillars that were involved directly with the Psychosocial team as part of the response system which were: Surveillance \& Epidemiology, Laboratory, Case Management, Evacuation and Decontamination.

Services process and Delivery - Psychosocial support work had 5 main streams for service delivery included; Support for Results Disclosure (RDS), Inpatient Care and Support (IPDS), Home Care support (HCS), Discharge and Follow up Care (DFC) and Health Care Worker Support Professional (HCWs). Other services rendered included Quarantine/Suspect Cases (QS) and Crises Management (CM). 
The virtual interventions and contact calls that were made in different streams were reported, logged and coded daily in a way to remove all clients' personal, identifiers and confidentiality was ensured only linked on data base that was in custody of the unit lead and overall lead. These virtual interventions utilised mainly included: Psychological First Aid procedures, along with a brief Mental Status Examination of willing patients. Other eclectic strategies were deployed as needed, namely; Counselling, Cognitive Behavioural Therapy (CBT) as needed, Supportive Psychotherapy, Cognitive Restructuring, Crises Intervention, while in few cases Psychopharmacology and regular Virtual support group sessions, including debriefing sessions for decommissioned frontline healthcare workers.

Reporting and Monitoring of team activities was ensured on a daily basis with supervision by team leads and direct unit coordination while peer and technical supervision was carried out weekly along with the capacity development sessions virtually.

The weekly reporting was done via records keeping, anonymised call logs within the teams, external regular communication to other adjacent pillars with case situation reports to the relevant teams. Feedback was given; to surveillance on patients concerns about infectivity in the family or contact tracing leads; to evacuation regarding clients willingness for evacuation or deterioration of symptoms; to laboratory regarding dilemmas over results and to case management for inpatients experiencing distress relating to the isolation, or those with acute mental health symptoms or in relation to prior mental health challenges. Central reports were also given, with daily reports from all pillars sent to the Incident Manager and weekly team reports made at the EOC. All EOC Reports appropriately collated and relayed to the Incident command system headed by the Incident Commander the State Governor, thereby guiding the overall State response.

Ethical Considerations - The approval for this work was obtained from the Lagos University Teaching Hospital (LUTH) Health and Research Ethics Committee (HREC). All the patients' personal identifiers were in custody of the unit coordinators and assigned to volunteers with only needed details for the task revealed to that specific therapist while other team members were blinded to the details. The central data was handled by the Pillar lead and the unit leads along with two other two members. General information sharing and reporting amongst team members were done using uniquely derived codes for each patient. Patients identified with evident mental health issues or symptoms requiring urgent specific psychiatric care were escalated to unit leads and then to the team lead who would then assign as needed to be managed by the crises unit of the team. Such patients were then referred to one of the three existing psychiatry health care units functioning within the state for more long-term care and follow up mental health treatment.

\section{Results}

The Multidisciplinary team was subdivided into working groups per response needs and service to be delivered. The three major professional groups represented were Medical doctors (Mental health experts and general doctors) 27\%, Clinical Psychologists 27\%, while the Social workers were 32\%. (Table 1).

The total number of support calls made by the Psychosocial support team for COVID-19 response in Lagos was well over 43,000 to the different categories of patients. The streams of services offered via these calls were Result Disclosure, Inpatient, Positive HCW, Home Support, Post Discharge, along with Crisis Management. Of these over 13,000 clients had their results disclosed to them while another, 1,316 patients were supported remotely while on inpatient isolation. Another 8000 calls were for patients being supported while at home and those followed up with 
a singular call after discharge. Virtual Frontline Healthcare Workers support group sessions began via Zoom Platform in June, in addition to the support calls being made (Table 2).

The services offered ranged from disclosure, through to inpatient services, home care support and follow up. Other aspects were crises management and quarantine support. Health workers were also uniquely supported. All services were somewhat linked to one another, though not all patients utilized all services in the course of their care. (Fig. 1).

Following result/diagnosis disclosure, majority of patients over time did not want to be evacuated to isolation unit this increased over time. By August as the home care program begun, admission into isolation units dropped sharply. (Table 3). Most admitted patients who received psychosocial support were male (61.8\%) and aged between 26 to 60 years) (See Table 4).

Various Psychosocial Support groups held, frequency and content varied according to the groups served. The support groups were for patients in home care, after discharge and in the course of supporting healthcare workers who were either volunteers of were being decommissioned from volunteering (Table 5).

Table 1

COVID-19 Psychosocial Support Team - Volunteer Composition

\begin{tabular}{|lll|}
\hline Psychosocial team Cadre & Number & Percentages \\
\hline Psychiatrist & 25 & $17 \%$ \\
\hline Other Medical Doctor & 15 & $10 \%$ \\
\hline Social Worker & 48 & $32 \%$ \\
Clinical Psychologist & 40 & $27 \%$ \\
\hline Others (Lay volunteer, health counsellor) & 22 & $15 \%$ \\
\hline Total & 150 & $100 \%$ \\
\hline
\end{tabular}

Table 2

Total Number of Psychosocial contacts made via Support Calls Per Intervention.

\begin{tabular}{|lllllll|}
\hline & May & June & July & August & September & Overall Total \\
\hline Result Disclosure* & 5073 & 7308 & 7888 & 1916 & 770 & 22,955 \\
\hline Inpatient* & 4300 & 2536 & 2343 & 708 & 80 & 9967 \\
\hline Positive HCW & 231 & 581 & 1384 & 245 & 328 & 2,769 \\
\hline Home Support Calls** & 0 & 2121 & 2209 & $0 * *$ & $0 * *$ & 4330 \\
\hline Post Discharge Calls & 0 & 247 & 2137 & 1284 & 127 & 3795 \\
\hline Crisis Management & 0 & 16 & 24 & 0 & 0 & 40 \\
\hline Total & 9604 & 12809 & 15985 & 4294 & 1305 & 43,856 \\
\hline
\end{tabular}

* Calls were made to same client averagely at 4 different times in the course of admission providing the needed support. This explains why the calls were so much more than the numbers of patients attended to on the different 
streams.

** Virtual Home support group sessions began via Zoom Platform in August.

Table 3. Pattern of Call Outcomes from Results Disclosure.

COVID 19 DATA

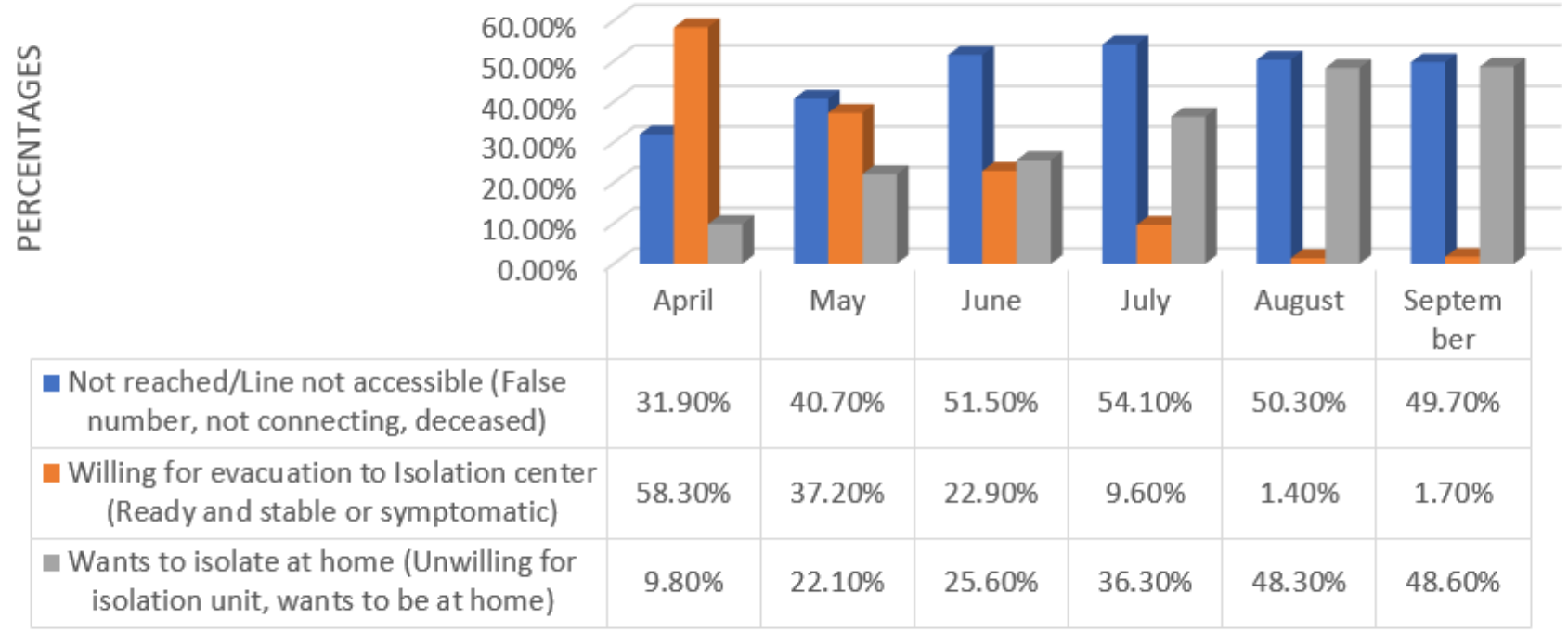

MONTHS

- Not reached/Line not accessible (False number, not connecting, deceased)

- Willing for evacuation to Isolation center (Ready and stable or symptomatic)

- Wants to isolate at home (Unwilling for isolation unit, wants to be at home) 
Table 4

- Gender and Age group of Inpatients Supported

\begin{tabular}{|lll|}
\hline & Frequency & Percent \\
\hline Gender & & \\
\hline Female & 439 & 33.4 \\
\hline Male & 813 & 61.8 \\
\hline Not Available & 64 & 4.9 \\
\hline Total & 1316 & 100.0 \\
\hline Age group & & \\
\hline $0-18$ & 58 & 4.4 \\
\hline $19-25$ & 102 & 7.8 \\
\hline $26-40$ & 542 & 41.2 \\
\hline $41-60$ & 441 & 33.5 \\
$61-99$ & 124 & 9.4 \\
\hline Total & 1267 & 96.3 \\
Unrecorded & 49 & 3.7 \\
\hline Total & 1316 & 100.0 \\
\hline
\end{tabular}


Table 5

- Psychosocial Support Groups

Home Care Support Groups

\begin{tabular}{|c|c|c|c|}
\hline & $\begin{array}{l}\text { Common Concern } \\
\text { Themes }\end{array}$ & Participants & Session Content \\
\hline \multirow{6}{*}{$\begin{array}{l}\text { Daily Zoom support group sessions. (Over } \\
70 \text { at time of this publication) }\end{array}$} & Results enquiry & $2-25$ per & \multirow{6}{*}{$\begin{array}{l}\text { Psychoeducation, } \\
\text { Relaxation exercises, } \\
\text { ventilation and queries by } \\
\text { participants, Linkages to } \\
\text { resources for support. }\end{array}$} \\
\hline & $\begin{array}{l}\text { Medication } \\
\text { advises }\end{array}$ & day. & \\
\hline & Fear of reinfection & & \\
\hline & $\begin{array}{l}\text { Concern for } \\
\text { family members }\end{array}$ & & \\
\hline & $\begin{array}{l}\text { Desire to retrieve } \\
\text { passports }\end{array}$ & & \\
\hline & $\begin{array}{l}\text { Participants - } \\
\text { ranged }\end{array}$ & & \\
\hline
\end{tabular}

Discharge support Groups

\begin{tabular}{|c|c|c|c|}
\hline & $\begin{array}{l}\text { Common Concern } \\
\text { Themes }\end{array}$ & Participants & Session Content \\
\hline \multirow[t]{6}{*}{ Weekly Discharge support group sessions } & Stigma & \multirow{2}{*}{$\begin{array}{l}\text { Over } 900 \\
\text { follow up } \\
\text { calls. }\end{array}$} & \multirow{2}{*}{$\begin{array}{l}\text { Coping with } \\
\text { discrimination of Covid- } \\
19\end{array}$} \\
\hline & Desire to forget & & \\
\hline & Covid 19 & \multirow{4}{*}{$\begin{array}{l}<100 \\
\text { willing for } \\
\text { group } \\
\text { sessions }\end{array}$} & Life after Covid 19 \\
\hline & aपाIISSIVII. & & Emotional Support and \\
\hline & Job loss. & & $\begin{array}{l}\text { Other care Post Covid19 } \\
\text { infection }\end{array}$ \\
\hline & Self Stigma. & & \\
\hline \multicolumn{4}{|c|}{ Debriefing sessions with decommissioned frontline healthcare workers } \\
\hline & $\begin{array}{l}\text { Common Concern } \\
\text { Themes }\end{array}$ & Participants & Session Content \\
\hline \multirow{5}{*}{$\begin{array}{l}\text { Weekly Zoom support group sessions with } \\
\text { decommissioned healthcare workers from } \\
\text { various pillars Covid-19 Response Team. } \\
\text { (Over } 10 \text { at time of this publication) }\end{array}$} & $\begin{array}{l}\text { Concerns were as } \\
\text { follows: }\end{array}$ & \multirow{5}{*}{$\begin{array}{l}6-47 \\
\text { participants } \\
\text { per session } \\
\text { per week. }\end{array}$} & $\begin{array}{l}\text { Mental Health on stress } \\
\text { management. }\end{array}$ \\
\hline & \multirow{2}{*}{$\begin{array}{l}\text { Testing positive to } \\
\text { COVID-19 as a } \\
\text { result of } \\
\text { occupational } \\
\text { hazard. }\end{array}$} & & $\begin{array}{l}\text { Psycho-education on } \\
\text { healthy living strategies } \\
\text { after disengagement. }\end{array}$ \\
\hline & & & Queries by participants. \\
\hline & $\begin{array}{l}\text { Infecting family } \\
\text { members if tested } \\
\text { positive. }\end{array}$ & & $\begin{array}{l}\text { Linking persons at risk of } \\
\text { psychological distress to } \\
\text { sources of support. }\end{array}$ \\
\hline & $\begin{array}{l}\text { Job loss and } \\
\text { stigmatization } \\
\text { post } \\
\text { decommissioning. }\end{array}$ & & \\
\hline
\end{tabular}




\section{Discussion}

Since Nigeria had its first case of corona virus diagnosed late in February 2020; there has been an increase in the number of people coming down with the disease. A wide range of mental health issues can occur at times of pandemics whether as a direct effect of the illness or as a consequence of the requirements for treatment including isolation and quarantine. Some of these mental health conditions include anxiety disorders, depression, delirium, substance use disorders. It is also important to note that the onset of a pandemic and its attendant implications may have an untoward effect on individuals with pre-existing mental health conditions. ${ }^{9}$ More specifically Wang and colleagues (2020) reported high rates of anxiety and depression among Chinese persons infected with the COVID-19

As with the best global practices the inclusion of mental health and psychosocial response team was set up as part of the larger Lagos state COVID-19 response team. A Psychosocial support team was constituted to offer the needed psychosocial services was an important piece in the wider response in caring for patients affected by the COVID-19 disease outbreak in the State.

The multidisciplinary composition of a psychosocial team with different cadres from the mental health field and lay persons as volunteers provide a robust team approach within an emergency response team. This ensured that key skills needed could be deployed promptly from within the team. Multidisciplinary teamwork is an encouraged strategy for any mental health and psychosocial support service in community disease outbreaks ${ }^{11}$.

Training of volunteers was provided on some key basic topics around COVID-19 diagnosis and management, Infection prevention and control. Other trainings were in psychological first aid, breaking of bad news techniques, coping skills, phone etiquette, utilisation of call guidance developed for the different calls and call log reporting process was put in place weekly. Knowledge on such topics has been found to allay a lot of fears in persons at risk or diagnosed with COVID-19 Infection.

In view of the highly infective nature of the corona virus along with the anticipated need for frequent and prolonged sessions when exploring mental health and psychosocial issues, the service delivery provided by this team was largely remote driven. There is good evidence that tele-health and face to face consultations can be equally effective. Service delivery was via; Tele-Mental health via remote technology platforms; Mobile phones, video calls, face to face consultation and group sessions were also provided.

At the outset of this index response, the psychosocial response began with the inpatient unit service supporting those on admission, over a short while it became evident as the response evolved that there was a need for the psychosocial team to support those receiving the COVID-19 diagnosis as many seemed to view the diagnosis as a death sentence fearing for their lives, reluctant for isolation and providing false data, thus making contact tracing difficult in those cases. Being grounded in the context of this community and being responsive to the needs of the population being served is a key attribute that effective response evolution of the team while on the field. This posture is recommended by the Inter Agency Standing Committee Reference Group for Mental Health and Psychosocial Support in Emergency Settings and summarises key mental health and psychosocial support (MHPSS) considerations in relation to the COVID-19 Pandemic and also further displayed in the response reports by Hyun (2020) et al in Korea where the teams' response also evolved with the needs of the population it served. ${ }^{11}$

The provision of telephonic result disclosure became imperative as the earlier weeks of the response revealed severe emotional reactions from individuals unprepared for a positive COVID-19 result. The Psychosocial team 
commenced providing disclosure using the SPIKES model of breaking bad news of positive COVID-19 result status to individuals, varied reactions were observed in the clients with many, on the one hand; there were several who also accepted the results, were grateful for the support and were willing to receive future support. On the other hand, however, others were refusing the results, which was understandably a maladaptive coping strategy of denial in the face of distressing news, querying the authenticity, refusing evacuation to isolation centers, and preferring to self-isolate at home.

Many countries including Nigeria have had to develop protocols for home self-isolation in the course of the response. The disclosure team routinely made effort to evaluate the level of knowledge about the virus and then educate the client on the next steps in the response and prepare them for other team members that will be in touch to provide care and support.

The patients treated in isolation centers received in patient support care, this mainly covered admission related concerns, requests for varied items from the isolation unit staff and requests for escalation of their medical needs since the care staff only came into the centers few times in the course of the day. Some experiences and concerns of patients while on admission included the concern about other loved ones at home, fear of their status and in a few cases actual guilt to have infected a family member was expressed. This is similar to reports of anxiety and distress among patients diagnosed with COVID-19.18

The home care support and discharge and follow up teams providing daily and weekly support groups along with follow up calls, respectively, helped unveil the psychological needs and answer medical questions in relation to the COVID-19 infection and the process of care. Issues around stigma and discrimination faced by the COVID-19 survivor was also important in the discharge follow up groups.

Frontline Healthcare workers were given a lot more detailed attention when identified either as a positive health care worker or as a frontline healthcare worker requiring mental health support in the course of providing care for patients within the State and also after decommissioning from the volunteer service in terms of; follow up calls and virtual debriefing/emotional support sessions. Structured psychosocial support was dedicated to these colleagues as part of the state response and details of this will be reported in another publication. General access to long term psychological follow up care is integrated into the COVID-19 follow up clinics.

Overall key findings in the course of Psychosocial support delivery found clients very anxious, in denial of their results and unwilling to be admitted into isolation centers. The reluctance for admission was mostly due to perceptions about the virus and initial fears that it may be a death sentence. The presence of fake news about causation and lack of trust in the disclosed results were also commonly expressed by clients all these along with accompanying anticipated stigma also made patients reluctant to accept the diagnosis nor cooperate with care in some of the clients. Crises management dealt with cases with overt complaints with core symptoms suggestive of a mental illness. These cases were handled in a lot more specific detail following clinical evaluation, mental status examinations, and regular follow up sessions. Some had to be formally referred and later commenced psychopharmaceutical agents. Besides, legal cases of stigma discrimination or unjust sack by employers concerning the COVID-19 diagnosis were escalated to the legal section of the state response via the incident manger to resolve.

Synchronisation of the entire response with other thematic areas on the response became an important strategy in the provision of Psychosocial support, which is a key item in the success planning for psychological support provision as part of pandemic responses as described by Inter-Agency Standing Committee, IASC Guidelines on 
Mental Health and Psychosocial Support in Emergency Settings ${ }^{16}$ Further in depth details and description of the different streams of the psychosocial support are in other publications.

\section{Challenges and Recommendations}

Challenges faced in the course of providing psychological support for patients in the COVID-19 pandemic were varied and these include; patients reluctance and anger around accepting the COVID-19 diagnosis, disbelief of diagnosis, frustration and uncertainty, secondary trauma to volunteers, while some patients expressed mistrust in the government systems.

Some challenges must be innovatively addressed by finding affordable and sustainable workable solutions while still ensuring continued close collaboration of multidisciplinary mental health team members with other response teams.

In the face of inadequate funding, psychosocial support runs a risk of being ignored at the expense of other more urgent acute life support services, however the long term emotional risk outcomes that may follow such a wide spread outbreak makes it is necessary for response agencies to cater to the funding of a basic psychosocial arm of a response to ensure a smooth flow of services and support of affected persons. Tele-health toll-free lines provision either by government or from donations from private agencies will be useful to offset the costs of emergency services like this which rely on telecommunications.

The stigma and shame associated with contracting the virus also was a deterrent for voluntary isolation, acceptance of positivity and voluntary testing in the early days of the outbreak. Funding for and conducting early public enlightenment campaigns targeted at behavioural change must be ongoing to assist in addressing these.

\section{Conclusion}

Mental health and Psychosocial support are an important part of any community-based response to disease outbreak as in the case of the COVID-19 pandemic. Affected persons require comprehensive support including mental health and psychosocial support through all the phases of the response. In resource deprived settings like Africa an adaptable and evolving multidisciplinary team can be set up and equipped to provide immediate and needs based emotional care to the population being served while also guiding towards long term mental health support of survivors.

\section{Declarations}

Ethics approval and consent to participate - This is largely an overview description of an intervention utilizing retrospective data. The approval for this work was obtained from the Lagos University Teaching Hospital (LUTH) Health and Research Ethics Committee (HREC).

Competing interests - Most of the authors serve as part of the Lagos State Covid19 response team. Nil any financial or other competing interests for the authors.

Data Sets - All data generated or analysed during this study are included in this published article. Other data sets used and/or analysed during the current study are available from the corresponding author on reasonable request. 
Funding - The funding for this program was supported by the Lagos State Ministry of Health.

Authors' contributions - all authors contributed to at least one or more roles in the preparation of this work ranging from conception, execution, analysis, writing the drafts and editing of this manuscript.

Acknowledgements - The team acknowledges the immense support of His Excellency the Governor of Lagos State, Mr. Babajide Sanwo-Olu for his role as the Incident commander and leadership of the State COVID-19 response.

Contributors - The following persons in the Psychosocial team supported extensively in the data collection and recording of all interactions documented and used in this publication.

Azeez Adebimpe Mariam, Oyebade Titilope Adeola , Bello Omolara , Yusuff Ganiat Olufunke, Ojiefoh Lulu Gethrude, Temitope Ajibola Aikomo, Idowu Joshua Tolulope, Ejiegbu Ngozi Anne, Ajayi Ayodeji Olubunmi, Chinelo Lynda Okeke, Ayanyemi Tunde Olabode, Oluwemimo David B, Akinniran Yetunde Ayanfunmilayo, Adebakin Sirajudeen Ademola, Sodimu Kehinde Aniyat, Adeeko Adeniyi John.

\section{References}

1. Gorbalenya AE, Baker SC, Baric RS, et al. Severe acute respiratory syndrome-related coronavirus: the species and its viruses-a statement of the Coronavirus Study Group. bioRxiv 2020; published online Feb 11. DOI:2020.02.07.937862 (preprint)

2. World Health Organozation. WHO Director-General's opening remarks at the media briefing on COVID-19 - 11 March 2020. Available from: https://www.who.int/dg/speeches/detail/who-director-w general-s-openingremarks-at-the-media-briefing-on-covid-19-11-march-2020 [Accessed 11th March 2020].

3. Nigeria Centre for Disease Control. First case of corona virus disease confirmed in Nigeria. Available from: https://ncdc.gov.ng/news/227/first-case-of-corona-virus-disease-confirmed-in-nigeria.

4. Nigerian Centre for Disease Control.Progression of COVID-19 cases in Nigeria Available from: https://covid19.ncdc.gov.ng/progression/

5. U.S. Department of Health and Human Services. Emergency Management and the Incident Command System.Available from:

https://www.phe.gov/Preparedness/planning/mscc/handbook/chapter1/Pages/emergencymanagement.aspx

6. This Day Newspapers Ltd. Coronavirus: Lagos Sets up Incident Command System to Prevent Outbreak. Available from: https://www.thisdaylive.com/index.php/2020/02/04/coronavirus-lagos-sets-up-incidentcommand-system-to-prevent-outbreak/

7. Lagos State Ministry of Health (Prof Akin Abayomi). Lagos State Preparedness Strategy. Available from:https://www.pharmaccess.org/wp-content/uploads/2020/03/covid-19-lagos-state-response.pdf [Accessed March,2020]

8. Dubey S, Biswas P, Ghosh R, et al. Psychosocial impact of COVID-19 [published online ahead of print, 2020 May 27]. Diabetes Metab Syndr. 2020;14(5):779-788. doi:10.1016/j.dsx.2020.05.035

9. Lahav Y. Psychological distress related to COVID-19 - The contribution of continuous traumatic stress [published online ahead of print, 2020 Aug 10]. J Affect Disord. 2020;277:12316.

doi:10.1016/j.jad.2020.07.141

10. Ravindran S, P LN, Channaveerachari NK, et al. Crossing barriers: Role of a tele-outreach program addressing psychosocial needs in the midst of COVID-19 pandemic. Asian J Psychiatr. 2020;53:102351. 
doi:10.1016/j.ajp.2020.102351

11. Hyun J, You S, Sohn S, et al. Psychosocial Support during the COVID-19 Outbreak in Korea: Activities of Multidisciplinary Mental Health Professionals. J Korean Med Sci. 2020;35(22):e211. Published 2020 Jun 8. doi:10.3346/jkms.2020.35.e211

12. Baile WF, Buckman R, Lenzi R, Glober G, Beale EA, Kudelka AP (2000) SPIKES - A SixStep Protocol for Delivering Bad News: Application to the Patient with Cancer. Oncologist 5:302-311

13. D. Huremović (2019): Psychiatry of Pandemics, Springer Nature Switzerland AG. https://doi.org/10.1007/9783-030-15346-5_1

14. Wang C, Pan R, Wan X, Tan Y, Xu L, Ho CS, Ho RC (2020): Immediate Psychological Responses and Associated Factors during the Initial Stage of the 2019 Coronavirus Disease (COVID-19) Epidemic among the General Population in China. Int. J. Environ. Res. Public Health 2020, 17, 1729; doi:10.3390/ijerph17051729

15. Baile WF, Buckman R, Lenzi R, Glober G, Beale EA, Kudelka AP (2000) SPIKES - A SixStep Protocol for Delivering Bad News: Application to the Patient with Cancer. Oncologist 5:302-311

16. Inter-Agency Standing Committee, IASC Guidelines on Mental Health and Psychosocial Support in Emergency Settings, 2009, ISBN 978-1-4243-3444-5, available at:

https://www.refworld.org/docid/4e97ceca2.html [accessed 15 October 2020]

17. Fardin, Mohammad Ali. (2020). COVID-19 and Anxiety: A Review of Psychological Impacts of Infectious Disease Outbreaks. Archives of Clinical Infectious Diseases. In Press. 10.5812/archcid.102779.

18. JP Rogers, E Chesney, D Oliver, TA Pollak, P McGuire, P Fusar-Poli, ... Psychiatric and neuropsychiatric presentations associated with severe coronavirus infections: a systematic review and meta-analysis with comparison to the COVID-19 pandemic. The Lancet Psychiatry Volume 7, Issue 7, July 2020, Pages 611-627

\section{Figures}

Service Flow for Diagnosis Disclosure
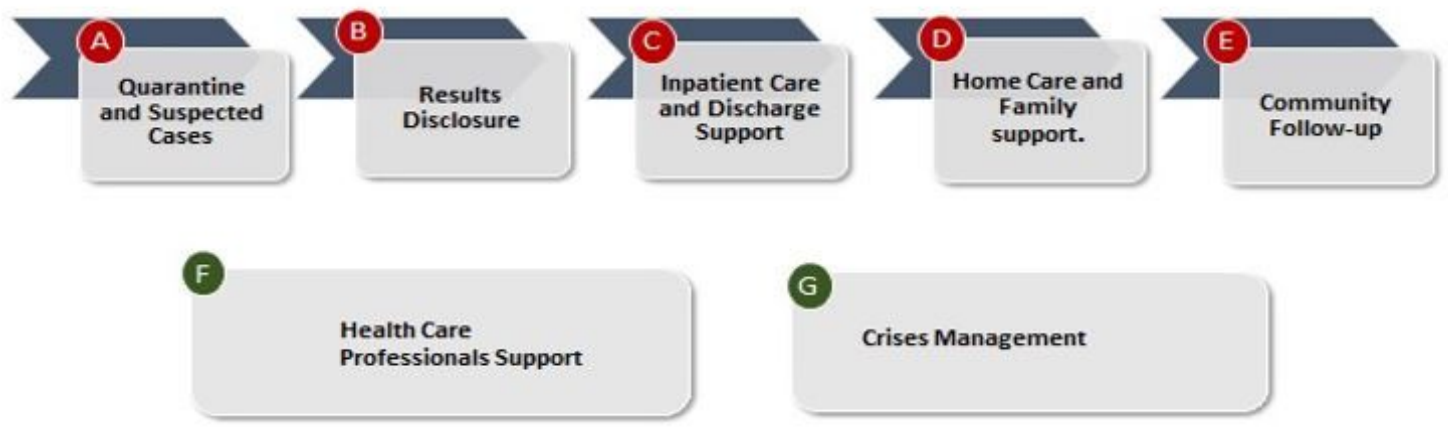

\section{Figure 1}

COVID-19 Psychosocial Support Service Flow 

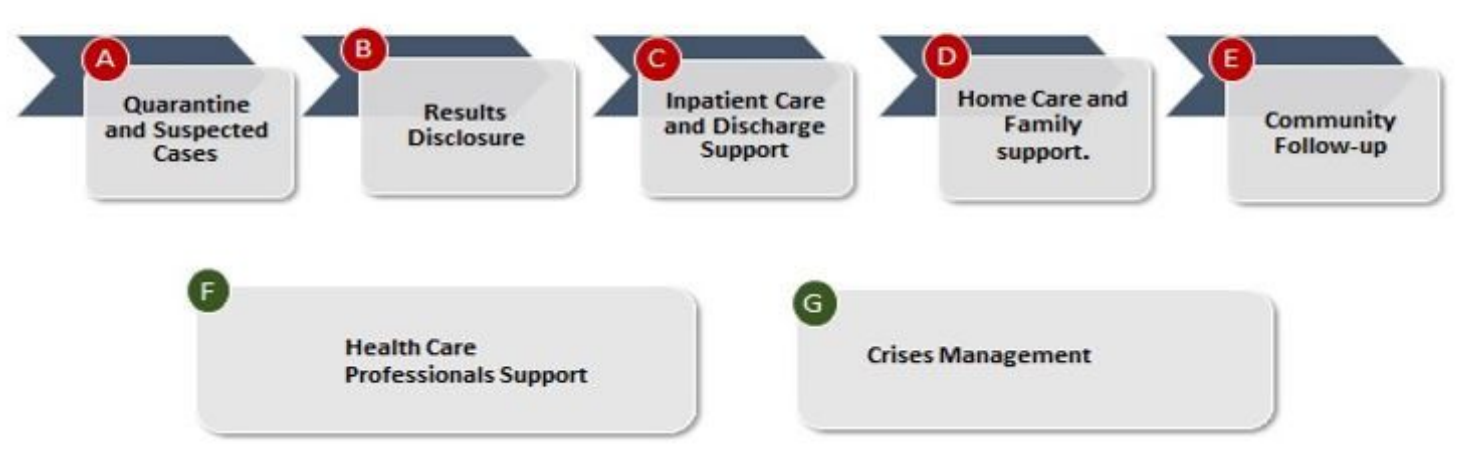

G

Crises Management

\section{Figure 1}

COVID-19 Psychosocial Support Service Flow 